\title{
Soja Grão e Caroço de Algodão em Suplementos Múltiplos para Terminação de Bovinos Mestiços em Pastejo
}

\section{Mário Fonseca Paulino1, 2, Edenio Detmann ${ }^{3}$, Sebastião de Campos Valadares Filho1, 2, Rogério de Paula Lana1, 2}

RESUMO - Dois experimentos foram conduzidos com o objetivo de avaliar suplementos múltiplos contendo soja grão (GSOI) e caroço de algodão (ALG) inteiros em relação a suplemento padrão de milho mais farelo de soja (FSOJA), em bovinos mestiços terminados a pasto, durante a época seca. Os suplementos foram balanceados para atingirem $20 \%$ PB, com base na matéria natural. Avaliaram-se, no primeiro experimento, as variáveis ganho médio diário (GMD - kg/dia), rendimento de carcaça quente (RC - \%) e peso de carcaça (PC - kg). Foram utilizados 12 novilhos mestiços Holandês-Zebu, com idade e peso médios iniciais de 24 meses e $361 \mathrm{~kg}$, manejados em três piquetes (3 ha) de Brachiaria decumbens, recebendo $4 \mathrm{~kg} / \mathrm{cab} /$ dia de suplemento. Observaram-se valores de GMD, RC e PC de 1,056, 52,21 e 241,20; 1,016, 53,04 e 242,55; e 1,137, 53,61 e 247,65, respectivamente, para os suplementos GSOI, ALG e FSOJA, que se mostraram equivalentes. No segundo experimento, objetivou-se avaliar a influência dos suplementos sobre o comportamento de pH e a concentração amoniacal ruminais. Empregaram-se os suplementos descritos inicialmente, acrescentando-se tratamento englobando a fonte protéica grão de soja moído (GSOM). Foram utilizados cinco novilhos mestiços, fistulados no rúmen, mantidos em piquete (3 ha) de Brachiaria decumbens, os quais receberam $4 \mathrm{~kg} / \mathrm{cab} / \mathrm{dia}$ de suplemento. As mensurações foram realizadas $0,2,4$ e 6 horas após a suplementação. $\mathrm{O}$ pH ruminal foi afetado por suplementos, sendo observadas quedas significativas somente em FSOJA, não ocorrendo, contudo, níveis danosos à microbiota ruminal. Os níveis amoniacais médios para ALG, GSOI e GSOM foram de 7,23; 6,91; e 6,74 mg/dL, respectivamente, não diferindo entre si, sendo inferiores ao FSOJA $(9,51 \mathrm{mg} / \mathrm{dL})$.

Palavras-chave: capim-braquiária, fermentação ruminal, ganho de peso, suplementação

\section{Whole Soybean and Cottonseed in Multiple Supplements for Fattening of Crossbred Cattle under Grazing}

\begin{abstract}
Two experiments were conducted to evaluate multiple supplements containing whole soybean (GSOI) and cottonseed (ALG) in relation to standard supplement of corn grain plus soybean meal (FSOJA) in crossbred steers finished at pasture, in the dry season. The supplements were balanced to reach the level of $20 \% \mathrm{CP}$, as fed basis. In the first experiment, average daily gain (ADG - $\mathrm{kg} / \mathrm{day}$ ), hot carcass dressing (CD -\%) and carcass weight (CW - kg) were evaluated. Twelve Holstein-Zebu crossbred steers, averaging 24 months old and initial weight of $361 \mathrm{~kg}$, were used and managed in three paddocks (3 ha each) of Brachiaria decumbens pasture, daily fed $4 \mathrm{~kg}$ of supplement per animal. The observed values of ADG, CD and CW were: 1.056, 52.21 and 241.20; 1.016, 53.04 and 242.55; and 1.137, 53.61 and 247.65, respectively, for the supplements GSOI, ALG and FSOJA, that showed to be equivalent. The objective of the second experiment was to evaluate the influence of the supplements on the behavior of ruminal $\mathrm{pH}$ and ammonia concentration. The supplements were those initially described, adding a treatment that included as protein source grinded soybean (GSOM). Five crossbred steers, fistulated in the rumen, grazing Brachiaria decumbens pasture and daily fed $4 \mathrm{~kg}$ of supplement, were used. The measures were performed at $0,2,4$ and 6 hours after supplementation. The ruminal $\mathrm{pH}$ was affected by the supplements, and significant reductions were observed only for FSOJA, however, no harmful levels to the ruminal microbes were observed. The average ammonia levels for ALG, GSOI and GSOM were of 7.23, 6.91 and $6.74 \mathrm{mg} / \mathrm{dL}$, respectively, and did not differ from each other, but were inferior than FSOJA $(9.51 \mathrm{mg} / \mathrm{dL})$.
\end{abstract}

Key Words: ruminal fermentation, signal grass, supplementation, weight gain

\section{Introdução}

O diferimento de pasto consiste em alternativa para reserva de forragem para a época seca. Entretanto, esta forragem é caracterizada por elevado teor de fibra e deficiências simultâneas de energia, proteína, minerais e vitaminas (Paulino, 1999). Para assegurar melhoria na utilização de forragens de baixa qualidade, é necessário suprir as deficiências de nutrientes dos microrganismos ruminais, ampliando sua taxa de crescimento e a extração de energia a partir dos carboidratos da forragem (Leng, 1990), condição que pode ser

\footnotetext{
${ }_{1}^{1}$ Professor - Departamento de Zootecnia, Universidade Federal de Viçosa. E.mail: mpaulino@mail.ufv.br

${ }^{2}$ Bolsista do CNPq.

${ }^{3}$ Zootecnista, DS, LEAG - UENF, Campos dos Goytacazes, RJ. E.mail: detmann@globo.com
} 
alcançada com o emprego de suplementos múltiplos.

A atividade dos microrganismos ruminais, principalmente aqueles que degradam carboidratos fibrosos, é dependente do nível amoniacal no rúmen. Baixas concentrações de amônia ruminal, comumente aquém das necessárias ao crescimento microbiano normal, são normalmente encontradas durante o período seco do ano, devido à queda na qualidade da forragem, marcadamente no tocante à disponibilidade protéica. O emprego de suplementos múltiplos tem alcançado sucesso em prover níveis de nitrogênio amoniacal mais adequados ao crescimento microbiano (DelCurto et al., 1990). Por outro lado, o fornecimento de concentrados apresenta influências diretas sobre o $\mathrm{pH}$ ruminal, podendo, em alguns casos, comprometer o crescimento microbiano (Hoover, 1986).

A formulação dos suplementos depende, além de aspectos nutricionais, dos objetivos traçados para o sistema de produção e do potencial produtivo da pastagem. Segundo Paulino (2000), quando se almeja a produção de novilhos precoces a pasto, com terminação coincidente com a época seca, que envolve ganhos superiores a $800 \mathrm{~g} / \mathrm{dia}$, deve-se liberalizar o consumo de suplementos, fornecendo-os na ordem de $0,8-1,0 \%$ do peso vivo (PV). Este processo constitui uma opção viável para os pecuaristas, pois, além de não requerer atividade agrícola para produção de volumosos, exige baixos investimentos em instalações e equipamentos e menor infra-estrutura. Em contrapartida, deve-se considerar que a natureza múltipla dos suplementos engloba também a flexibilidade em sua composição, em que o emprego de alimentos de disponibilidade caracteristicamente regional, como a soja em grão e o caroço de algodão, constitui alternativa para redução de custos na formulação desses.

Objetivou-se, neste estudo, contrastar suplementos formulados com soja grão e caroço de algodão inteiros com um suplemento padrão de milho e farelo de soja, com relação ao desempenho e rendimento de carcaça de novilhos mestiços terminados a pasto durante a época seca, avaliando-se, paralelamente, os efeitos da suplementação sobre o comportamento do $\mathrm{pH}$ e da concentração amoniacal ruminais.

\section{Material e Métodos}

\section{Experimento 1}

O experimento foi conduzido na Central de Experimentação, Pesquisa e Extensão do Triângulo Universidade Federal de Viçosa, Capinópolis-MG, no período de 23 de junho a 25 de setembro de 1999.

A área experimental era composta de três piquetes de três hectares, cobertos uniformemente com a gramínea Brachiaria decumbens, providos de bebedouro e comedouro cobertos. O diferimento da pastagem foi realizado por intermédio da vedação dos piquetes à entrada de animais, a partir de meados do mês de março de 1999.

Os tratamentos avaliados constituíram suplementos formulados à base de milho grão, mistura mineral, uréia e sulfato de amônia, fornecidos na quantidade de $4 \mathrm{~kg} / \mathrm{animal} / \mathrm{dia}$, variando-se as seguintes fontes protéicas:

T1. Farelo de soja (FSOJA)

T2. Caroço de algodão inteiro (ALG)

T3. Soja em grão inteiro (GSOI)

Todos os suplementos foram balanceados, segundo análise prévia dos alimentos, para atingirem $20 \%$ de proteína bruta (PB), com base na matéria natural. A composição alimentar dos suplementos é descrita na Tabela 1 . O fornecimento foi realizado em comedouro conjunto, às $10 \mathrm{~h}$, visando minimizar a interferência sobre o comportamento de pastejo da manhã e a ocorrência de efeito substitutivo sobre o consumo de matéria seca (Adams, 1985).

Foram empregados 12 novilhos mestiços Holandês-Zebu, com idade e peso médios iniciais de 24 meses e $361 \mathrm{~kg}$, os quais foram distribuídos aleatória e balanceadamente entre tratamentos. As pesagens inicial e final dos animais foram realizadas com base no peso vivo obtido após 18 horas de jejum de água e alimentos, com o objetivos de reduzir a diferença entre animais com relação ao enchimento do trato digestivo (Escuder, 1975). Realizaram-se pesagens periódicas, a cada 28 dias, as quais coincidiram com a rotação de tratamentos entre piquetes, a fim de eliminar possíveis variações devidas a esta fonte, perfazendo, portanto, um total de três períodos de avaliação, com 28 dias cada.

Ao término deste período, os animais foram abatidos por intermédio de concussão cerebral, seguida 
por secção da veia jugular, sendo avaliado logo após o abate o peso de carcaça quente, o qual serviu como base para estimação do rendimento de carcaça.

As avaliações quantitativas e qualitativas da pastagem foram realizadas durante a parte central do segundo período, as quais foram consideradas, então, como estimativas médias para todo o período experimental. A estimação da disponibilidade total de massa forrageira foi realizada por intermédio do corte, ao nível do solo, de cinco áreas, delimitadas por um quadrado metálico de 1 x $1 \mathrm{~m}$, escolhidas aleatoriamente dentro de cada piquete (McMeniman, 1997), as quais foram pesadas e homogeneizadas, retirando-se uma alíquota para determinação do teor de matéria seca (MS). A avaliação da dieta ingerida pelos animais se deu por simulação manual de pastejo, após observação prévia do comportamento ingestivo dos animais. As amostras obtidas, em conjunto com a alíquota destinada à estimação de disponibilidade, foram imediatamente conduzidas a estufa de ventilação forçada $\left(60^{\circ} \mathrm{C}\right)$, por 72 horas, sendo então processadas em moinho tipo Willey, com peneira de $1 \mathrm{~mm}$ e acondicionadas em frascos de polietileno para análise posterior.

Todas as análises laboratoriais foram realizadas no Laboratório de Nutrição Animal do Departamento

Tabela 1 - Composição alimentar percentual, com base na matéria natural, dos diferentes suplementos

Table 1 - Percentage feed composition, as fed basis, according to the supplements

\begin{tabular}{|c|c|c|c|}
\hline \multirow[b]{2}{*}{$\begin{array}{l}\text { Ingrediente } \\
\text { Ingredient }\end{array}$} & \multicolumn{3}{|c|}{$\begin{array}{l}\text { Suplementos } \\
\text { Supplements }\end{array}$} \\
\hline & FSOJA & GSOI & ALG \\
\hline $\begin{array}{l}\text { Sal mineral }^{1} \\
\text { Mineral salt }\end{array}$ & 2,0 & 2,0 & 2,0 \\
\hline $\begin{array}{l}\text { Uréia/Sulfato de amônia }(9: 1) \\
\text { Urea/Ammonia sulfate }(9: 1)\end{array}$ & 2,5 & 2,5 & 2,5 \\
\hline $\begin{array}{l}\text { Farelo de soja } \\
\text { Soybean meal }\end{array}$ & 17,0 & - & - \\
\hline $\begin{array}{l}\text { Grão de soja } \\
\text { Whole soybean }\end{array}$ & - & 25,0 & - \\
\hline $\begin{array}{l}\text { Caroço de algodão } \\
\text { Cottonseed }\end{array}$ & - & - & 50,0 \\
\hline $\begin{array}{l}\text { Milho grão triturado } \\
\text { Grinded corn grain }\end{array}$ & 78,5 & 70,5 & 45,5 \\
\hline $\begin{array}{l}1 \text { Composição percentual: fosfato b } \\
48,61 \text {; sulfato de zinco, } 1,46 ; \text { su } \\
\text { magnésio, } 0,50 \text {; sulfato de cobalto, } \\
\text { Percentage composition: dicalcium pho } \\
\text { zinc sulfate, } 1.46 \text {; coppersulfate, } 0.72 ; m \\
.05 \text {; and potassium iodate, } .05 \text {. }\end{array}$ & $\begin{array}{l}\text { álcico, } 48 \\
\text { ato de cc } \\
0,05 ; \text { e ioc } \\
\text { fate, } 48.61 \\
\text { gnesiums }\end{array}$ & $\begin{array}{l}\text { cloret } \\
0,72 \text {; } \\
\text { de pot } \\
\text { dium ch } \\
, 0.50 ;\end{array}$ & $\begin{array}{l}\text { sódio, } \\
\text { ato de } \\
0,05 . \\
48.61 \text {; } \\
\text { sulfate, }\end{array}$ \\
\hline
\end{tabular}

R. Bras. Zootec., v.31, n.1, p.484-491, 2002 (suplemento) de Zootecnia da Universidade Federal de Viçosa. As amostras de suplementos e pastejo simulado foram avaliadas quanto aos teores de MS, PB, fibra em detergente neutro $(\mathrm{FDN})$, extrato etéreo (EE) e cinzas, conforme técnicas descritas por Silva (1990). Os resultados das análises são demonstrados na Tabela 2.

$\mathrm{O}$ experimento foi conduzido em delineamento inteiramente casualizado, segundo o modelo:

$$
\mathrm{Y}_{\mathrm{ij}}=\mathrm{m}+\mathrm{S}_{\mathrm{i}}+\mathrm{e}(\mathrm{i}) \mathrm{j}
$$

em que: $Y_{i j}=$ observação correspondente ao suplemento i e à repetição $\mathrm{j} ; \mathrm{m}=$ constante geral; $\mathrm{S}_{\mathrm{i}}=$ efeito referente ao suplemento $i$, sendo $i=1,2$ e 3 ; e e(i)j $=$ erro aleatório, associado a cada observação, pressuposto NID $\left(0, \mathrm{I}^{2}\right)$.

Todas as análises estatísticas foram realizadas empregando-se o programa SAEG, adotando-se $\alpha=0,05$.

\section{Experimento 2}

O experimento foi realizado nos meses de agosto e setembro de 1999 na Central de Experimentação Pesquisa e Extensão do Triângulo - Universidade Federal de Viçosa, Capinópolis-MG.

Foram utilizados cinco novilhos mestiços holandês-zebu, castrados, fistulados no rúmen, mantidos em piquete de Brachiaria decumbens, com área de

Tabela 2 - Teores médios, em porcentagem da matéria seca (MS), de matéria orgânica (MO), proteína bruta (PB), fibra em detergente neutro (FDN), cinzas e extrato etéreo (EE) para os diferentes suplementos e para as amostras de simulação de pastejo (PS)

Table 2 - Mean concentration (\%) of dry matter (DM), organic matter (OM), crude protein (CP), neutral detergent fiber (NDF), ash and ether extract (EE), in dry matter basis, for different supplements and hand-plucking samples (PS)

\begin{tabular}{lccccc}
\hline & \multicolumn{5}{c}{ Suplementos $^{1}$} \\
& \multicolumn{5}{c}{ Supplements $^{1}$} \\
\cline { 2 - 6 } & GSOI & GSOM & FSOJA & ALG & PS \\
\hline MS & 89,36 & 89,28 & 89,20 & 89,50 & 64,05 \\
MO & 86,21 & 84,67 & 85,82 & 86,14 & 82,26 \\
OM & & & & & \\
PB & 21,64 & 23,31 & 22,81 & 22,69 & 2,52 \\
CP & & & 14,81 & 30,80 & 75,09 \\
FDN & 16,20 & 16,89 & & & \\
NDF & & 5,33 & 4,18 & 3,86 & 7,74 \\
Cinzas & 3,79 & 5,33 & & & $*$ \\
Ash & 7,89 & 7,90 & 3,20 & 12,16 & $*$ \\
EE & & & & & \\
\hline$E$
\end{tabular}

*não-estimado (not estimated). 
3 ha. O experimento foi realizado em quatro períodos experimentais de oito dias, sendo os sete primeiros de adaptação.

Foram empregados suplementos balanceados para atingirem o nível de $20 \%$ de proteína bruta com base na matéria natural, compostos por milho grão, uréia e sal mineral, utilizando-se as seguintes fontes protéicas:

- T1. Farelo de soja (FSOJA);

- T2. Caroço de algodão inteiro (ALG);

- T3. Soja em grão inteiro (GSOI); e

- T4. Soja em grão moído (GSOM).

Os suplementos foram fornecidos na quantidade de $4 \mathrm{~kg} / \mathrm{animal} / \mathrm{dia}$, às $10 \mathrm{~h}$. Todos os animais receberam, conjuntamente, o mesmo suplemento durante o período experimental, cuja composição alimentar é descrita na Tabela 1. Ressalta-se que os suplementos GSOI e GSOM apresentaram formulação semelhante, diferindo apenas em termos de moagem ou não do grão de soja.

No oitavo dia de cada período, foram realizadas coletas de líquido ruminal, na região de interface líquido:sólido, imediatamente antes e 2, 4 e 6 horas após o fornecimento dos suplementos. As amostras foram filtradas por uma camada tríplice de gaze e, imediatamente, analisadas quanto ao seu $\mathrm{pH}$, em peagâmetro digital. Retiraram-se, então, alíquotas de $40 \mathrm{~mL}$, que foram fixadas com $1 \mathrm{~mL}$ de $\mathrm{HCl}(1: 1)$, em vidros com tampa de polietileno, congeladas a $-20^{\circ} \mathrm{C}$, para posterior análise do teor de $\mathrm{N}$-amoniacal.

A avaliação qualitativa da pastagem foi realizada semelhante e concomitantemente ao Experimento 1, uma vez que o período avaliativo foi coincidente e o piquete empregado neste experimento, semelhante e adjacente àqueles descritos anteriormente. Assim, a composição média de amostras obtidas por simulação manual de pastejo foi expressa em conjunto ao Experimento 1 (Tabela 2).

As análises de suplementos e pastejo simulado foram conduzidas conforme descrito no Experimento 1, sendo os resultados expressos na Tabela 2. As amostras de líquido ruminal foram descongeladas à temperatura ambiente e centrifugadas a 1000 x G, por 15 minutos, para remoção do excesso de sólidos, sendo então analisadas quanto ao teor de nitrogênio amoniacal $\left(\mathrm{N}-\mathrm{NH}_{3}\right)$, por intermédio de método colorimétrico (Chaney \& Marbach, 1962).

O experimento foi analisado em delineamento de blocos casualizados, sendo os animais considerados blocos, adotando-se esquema de subdivisão de parcelas em função dos tempos de coleta, segundo o modelo:

$$
\mathrm{Y}_{\mathrm{ijk}}=\mathrm{m}+\mathrm{S}_{\mathrm{i}}+\mathrm{A}_{\mathrm{j}}+\mathrm{e}_{\mathrm{ij}}+\mathrm{T}_{\mathrm{k}}+\mathrm{ST}_{\mathrm{ik}}+\mathrm{e}(\mathrm{ij}) \mathrm{k}
$$

em que: $Y_{i j k}=$ observação referente ao suplemento $i$, animal j e tempo $\mathrm{k} ; \mathrm{m}=$ constante geral; $\mathrm{S}_{\mathrm{i}}=$ efeito referente ao suplemento $i$, sendo $i=1,2,3$ e 4; $A_{j}=$ efeito referente ao animal (bloco) $j$, sendo $j=1$, 2, 3, 4 e 5; eij = efeito residual das parcelas; $\mathrm{T}_{\mathrm{k}}=$ efeito referente ao tempo de coleta $\mathrm{k}$, sendo $\mathrm{k}=1,2,3$ e 4; $\mathrm{ST}_{\mathrm{ik}}=$ efeito de interação entre o suplemento i e tempo de coleta $\mathrm{k}$; e e (ij)k = erro aleatório, associado a cada observação, pressuposto $\operatorname{NID}\left(0, I \sigma^{2}\right)$.

Todas as análises foram realizadas utilizando-se o programa SAEG. As comparações entre médias foram realizadas por meio de análise de regressão linear e teste Student Newman Keulls (SNK), adotando-se $\alpha=0,05$.

\section{Resultados e Discussão}

\section{Experimento 1}

As médias para as variáveis ganho de peso diário e rendimento de carcaça são apresentadas na Tabela 3 .

A forragem disponível apresentou baixo teor de proteína $(2,52 \%)$ e alto conteúdo de fibra $(75,09 \%$ de FDN) (Tabela 2), substrato que enseja baixo desempenho animal. Entretanto, a suplementação proporcionou ganhos de peso de 1,056; 1,016; e 1,137 kg/ animal/dia para os suplementos contendo soja grão inteira (GSOI), caroço de algodão inteiro (ALG) e milho e farelo de soja (FSOJA), respectivamente, não havendo diferença estatística significativa $(\mathrm{P}>0,05)$. Estes suplementos atenderam cerca de 40 e $80 \%$ das exigências de matéria seca e proteína bruta, respectivamente, conforme o NRC (1988). Admite-se, portanto, que, embora não tenha sido conduzido tratamento controle (sem suplementação), o fornecimento de suplementos que atendam $80 \%$ das exigências de proteína e $40 \%$ de energia, associado a níveis adequados de minerais e vitaminas, cria condições de fermentação no rúmen que estimulam consumo e digestão da forragem de qualidade inferior, possibilitando liberação de energia suficiente para ganhos de peso satisfatórios.

Ganhos de peso semelhantes aos obtidos neste estudo foram encontrados por Euclides et al. (1997), empregando suplementos compostos por farelo de soja e milho desintegrado com palha e sabugo, no nível de 0,8\% PV. Entretanto, no segundo ano de condução do experimento, os ganhos mostraram-se inferiores aos relatados neste estudo $(0,551-0,613 \mathrm{~kg} /$ cabeça/dia). Segundo estes autores, neste período, a 
Tabela 3 - Médias e coeficientes de variação para as variáveis pesos vivos médios inicial e final (PVI e PVF), ganho de peso diário (GPD), rendimento de carcaça (RC) e peso de carcaça (PC) para os diferentes tratamentos

Table 3 - Mean and coefficient of variation for the variables initial and final live weights (ILW and FLW), average daily gain (ADG), carcass dressing $(C D)$ and carcass weight $(C W)$, according to the treatments

\begin{tabular}{|c|c|c|c|c|c|}
\hline & \multicolumn{3}{|c|}{$\begin{array}{l}\text { Suplementos } \\
\text { Supplements }\end{array}$} & \multirow[b]{2}{*}{$\begin{array}{l}\text { Média } \\
\text { Mean }\end{array}$} & \multirow[b]{2}{*}{$\mathrm{CV}(\%)$} \\
\hline & FSOJA & GSOI & ALG & & \\
\hline $\begin{array}{l}\text { PVI }(\mathrm{kg})^{1} \\
I L W(k g)^{l}\end{array}$ & $356,50 \pm 7,49$ & $363,25 \pm 11,41$ & $363,00 \pm 6,41$ & 360,9 & - \\
\hline $\begin{array}{l}\operatorname{PVF}(\mathrm{kg})^{2} \\
F L W(\mathrm{~kg})^{2}\end{array}$ & 462,25 & 461,50 & 457,50 & 460,42 & 5,88 \\
\hline $\begin{array}{l}\mathrm{GPD}(\mathrm{kg})^{2} \\
A D G(\mathrm{~kg})^{2}\end{array}$ & 1,137 & 1,056 & 1,016 & 1,070 & 28,44 \\
\hline $\begin{array}{l}\mathrm{RC}(\%)^{2} \\
C D(\%)^{2}\end{array}$ & 53,61 & 52,21 & 53,04 & 52,96 & 3,59 \\
\hline $\begin{array}{l}\mathrm{PC}(\mathrm{kg})^{2} \\
C W(\mathrm{~kg})^{2}\end{array}$ & 247,65 & 241,20 & 242,55 & 243,75 & 6,71 \\
\hline
\end{tabular}

pastagem advinha de período contínuo de pastejo, não havendo, portanto, vedação para o diferimento, o que comprometeu a qualidade da forragem disponível. Por outro lado, Paulino (2000) afirmou que alta oferta de forragem possibilita ao bovino pastejar seletivamente, sendo condição desejável, notadamente em sistemas de bovinos de corte, pois permite ganhos de peso mais elevados, favorecendo o rendimento animal em sistemas de ciclo curto. Dessa forma, a boa disponibilidade de forragem encontrada neste estudo (6025,7 kg de MS/ha; CV = 17,4\%) poderia, em parte, justificar os ganhos superiores aos apresentados por Euclides et al. (1997), cuja disponibilidade durante o respectivo período foi de $2100 \mathrm{~kg}$ de $\mathrm{MS} / \mathrm{ha}$.

Os resultados demonstrados neste estudo corroboram os relatos de Santos (2001), que encontrou, ao fornecer suplementos constituídos por farelo de soja, farelo de trigo e milho (20\% PB) a novilhos F1 Limousin X Nelore em pastagem de B. decumbens, no nível de $1,0 \%$ do PV, ganhos médios de $0,915 \mathrm{~kg} /$ dia. Semelhantemente, Detmann et al. (2001) observaram ganhos de $0,982 \mathrm{~kg} /$ dia em novilhos mestiços Holandês X Zebu, manejados em pastagem de $B$. decumbens, recebendo suplementos constituídos por milho e soja grão $(20 \% \mathrm{~PB})$, em quantidade semelhante à empregada neste estudo. Santos (2001) e Detmann et al. (2001) trabalharam com elevada disponibilidade de matéria seca na pastagem, obtendo-se 7902 e $7000 \mathrm{~kg} / \mathrm{ha}$, respectivamente.

Semelhantemente ao ganho de peso diário, não se observou diferença significativa entre suplementos para a variável rendimento de carcaça $(\mathrm{P}>0,05)$. Os resultados obtidos assemelham-se àqueles descritos por Santos (2001), que encontrou rendimento de carcaça médio de 53,6\% em novilhos F1 Limousin X Nelore terminados de forma semelhante à empregada neste estudo. Por outro lado, o valor médio encontrado mostrou-se semelhante aos relatados por Thiago et al. (1998) e Alcalde et al. (2000) para novilhos Pardo Suíço X Nelore $(54,3 \%)$ e Simental XNelore (53,61\%), respectivamente, em condições de confinamento. Observam-se, conjuntamente, valores comercialmente satisfatórios para a variável peso de carcaça, a qual não foi afetada por suplementos $(\mathrm{P}>0,05)$. Assim, infere-se que a terminação de bovinos em pastejo pode apresentar resultados de desempenho produtivo semelhantes àqueles encontrados em animais oriundos de confinamentos, constituindo, portanto, alternativa tecnicamente viável para produção de carne durante o período seco. Segundo Euclides et al. (1997), a decisão de engordar bovinos em condições de pastejo, utilizando suplementação, ou em confinamento, dependerá da condição particular da região e do mercado. A implementação de qualquer destes sistemas pode viabilizar o abate de animais mais jovens, com carcaça de melhor qualidade, e aumentar a capacidade de suporte da propriedade.

Infere-se que, garantida a disponibilidade de forragem para pastejo adequado durante o período seco do ano, aliada à flexibilidade na composição dos suplementos, adequando-os à realidade regional, a termina- 
ção de bovinos em pastagens durante o período seco constitui alternativa viável para condições tropicais.

\section{Experimento 2}

Os valores de $\mathrm{pH}$ ruminal não sofreram influências diretas de suplemento $(\mathrm{P}>0,05)$, observando-se, contudo, efeitos significativos quanto ao tempo de coleta $(\mathrm{P}<0,01)$ e interação suplemento $\mathrm{x}$ tempo $(\mathrm{P}<0,01)$. A análise de regressão, em função dos tempos de coleta, demostrou distinção entre suplementos (Figura 1). Reduções significativas no $\mathrm{pH}$ foram observadas somente para o suplemento FSOJA $(\mathrm{P}<0,05)$.

Segundo dados de Kowalczyk et al. (1977), a adição de gordura na dieta influencia positivamente o $\mathrm{pH}$ ruminal. Neste enfoque, especula-se que o alto teor de extrato etéreo observado para os suplementos compostos por sementes oleaginosas gerou efeito tamponante sobre o pH ruminal, o que justifica a inalteração observada em ALG e GSOM e a ligeira elevação observada em GSOI. Mesmo de posse destes fatos, observa-se que os valores encontrados, mesmo os inferiores extremos, encontram-se acima de 6,0, onde, segundo Hoover (1986), iniciariam-se os efeitos deletérios sobre a microbiota celulolítica ruminal.

A concentração amoniacal foi afetada tanto por suplemento $(\mathrm{P}<0,05)$, como por tempo $(\mathrm{P}<0,01)$, não

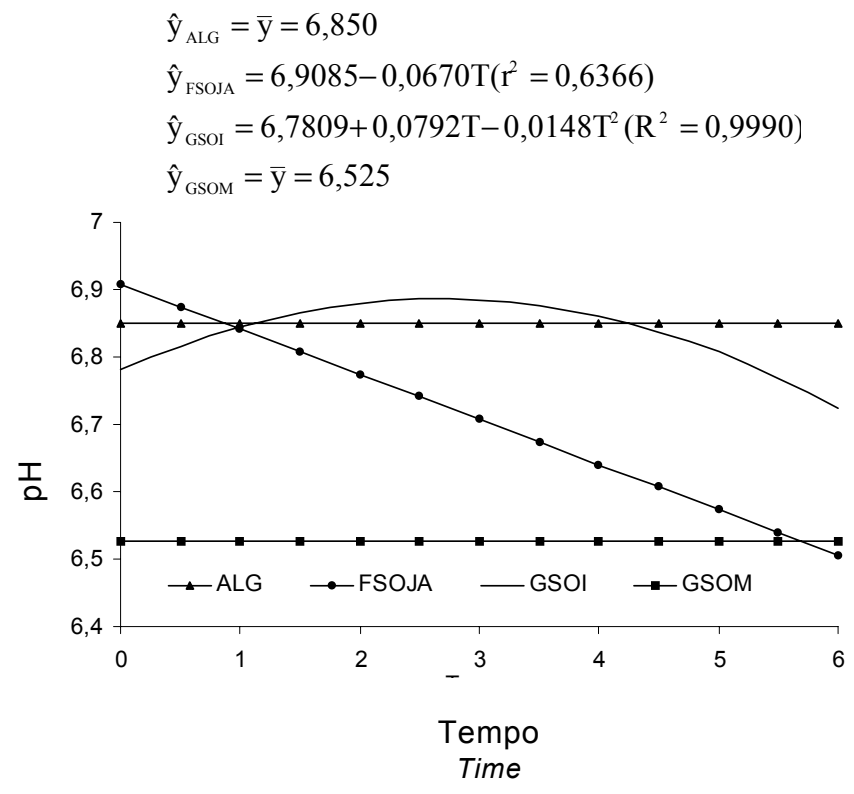

Figura 1 - Estimativas do pH ruminal, em função dos tempos (T) pós-suplementação (horas), para cada tratamento.

Figure 1 - Estimates of ruminal $\mathrm{pH}$ in function of time $(T)$ after supplementation (hours), for each treatment. havendo, contudo, efeito de interação entre os fatores $(\mathrm{P}>0,05)$. Para avaliação do comportamento amoniacal, em função do tempo pós-suplementação estabeleceu-se superfície de resposta, incluindo-se o fator qualitativo suplemento, por intermédio da técnica de alocação de valores, conforme Searle (1971) (Figura 2). Observa-se que os níveis basais (tempo $=0$ ) se mostraram extremamente reduzidos, abaixo do mínimo de $5 \mathrm{mg} / \mathrm{dL}$ preconizados pelo NRC (1988) para digestão eficiente da matéria orgânica no ambiente ruminal. Isto é justificado pelo baixo teor protéico observado para a pastagem (Tabela 2), a qual não se mostrou capaz de suprir o mínimo de $1 \%$ de nitrogênio dietético exigido para o metabolismo adequado dos microrganismos ruminais (Minson, 1990). O comportamento quadrático observado foi condizente com o descrito por DelCurto et al. (1990), sendo a implementação dos níveis considerada satisfatória. Embora o coeficiente de regressão para o fator suplemento tenha sido significativo $(\mathrm{P}<0,05)$, a análise para as médias globais de concentração demonstrou não haver diferença entre as sementes oleaginosas $(\mathrm{P}>0,05)$, as quais foram inferiores ao FSOJA $(\mathrm{P}<0,05)$ (Tabela 4$)$.

Esta diferença encontrada entre os grãos oleaginosos e o farelo de soja pode ser justificada ao se

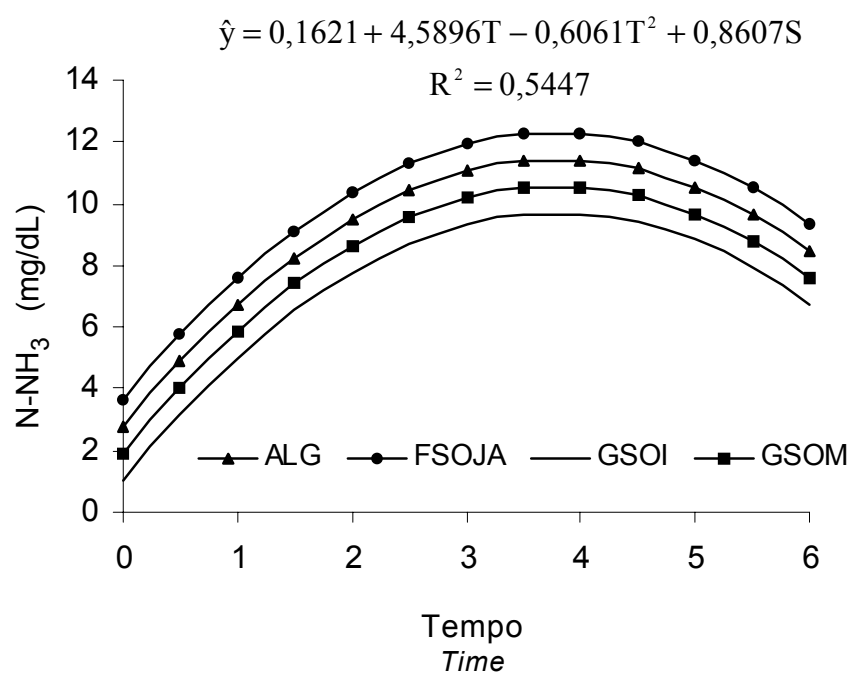

Figura 2 - Estimativas para a concentração amoniacal ruminal, em função dos tempos ( $T$ ) póssuplementação (Cortes para a superfície de resposta obtidos pela fixação do fator qualitativo suplemento (S): GSOI = 1; GSOM = 2; ALG = 3; FSOJA = 4).

Figure 2 - Estimates for ammonia ruminal concentration in function of collection times (T) after supplementation (cuts for response surface by fixation of qualitative factor supplement (S): $G S O I=1 ; G S O M=2 ; A L G=3 ; F S O J A=4$ ). 
Tabela 4 - Médias gerais para a concentração de amônia ruminal ( $\mathrm{mg} / \mathrm{dL}$ ) em função dos diferentes suplementos

Table 4 - Overall means for ruminal ammonia concentration (mg/ $d L)$, according to the supplements

\begin{tabular}{|c|c|c|c|c|}
\hline & \multicolumn{4}{|c|}{$\begin{array}{l}\text { Suplementos } \\
\text { Supplements }\end{array}$} \\
\hline & GSOI & GSOM & FSOJA & ALG \\
\hline $\begin{array}{l}\text { Amônia ruminal }^{1} \\
\text { Ruminal ammonia }^{1}\end{array}$ & $6,74^{b}$ & $6,91^{b}$ & $9,51^{\mathrm{a}}$ & $7,23^{b}$ \\
\hline
\end{tabular}

${ }^{1}$ Médias, na linha, seguidas por letras diferentes, são diferentes $(P<0,05)$ pelo teste SNK

${ }^{1}$ Means, within a row, followed by different letters, are different $(P<.05)$ by SNK test.

analisarem as taxas de degradação da proteína expostas por Sniffen et al. (1992), as quais apresentam pouca variação entre o caroço de algodão e grão de soja cru, sendo, no entanto, mais elevadas para o farelo de soja. Por outro lado, Nagaraja et al. (1997) afirmaram que a elevação do nível de gordura da dieta, fato demonstrado nesta pesquisa pela adição de sementes oleaginosas ao suplemento, incrementa a eficiência de síntese de proteína microbiana e, conseqüentemente, a assimilação de amônia. Paralelamente, o decréscimo na concentração amoniacal pode, ainda, estar relacionado à redução da proteólise, associada com a menor atividade dos protozoários. Estas afirmativas corroboram o fato de o aumento da superfície específica para o ataque microbiano, obtido pela moagem do grão de soja, não ter se mostrado capaz de afetar os níveis amoniacais, quando comparado ao fornecimento do grão integral. Infere-se, contudo, que todas as fontes empregadas foram eficientes em implementar os níveis de amônia no rúmen.

\section{Conclusões}

O emprego de grão de soja ou caroço de algodão em suplementos para terminação de bovinos em pastejo, durante a época seca, propiciou desempenho animal semelhante ao obtido com a fonte protéica padrão farelo de soja.

A utilização de suplementos múltiplos na quantidade de $4 \mathrm{~kg} /$ animal/dia para terminação de bovinos em pastejo não é capaz de alterar o $\mathrm{pH}$ ruminal em níveis biologicamente indesejados. Por outro lado, as diferentes fontes de proteína empregadas neste estudo mostraram-se eficientes em implementar os níveis de amônia no rúmen, tornando este ambiente mais propício ao crescimento microbiano, durante a época seca do ano.

\section{Literatura Citada}

ADAMS, D.C. Effect of time of supplementation on performance, forage intake and grazing behavior of yearling beef steers grazing Russian wild ryegrass in the fall. Journal of Animal Science, v.61, p.1037-1042, 1985.

ALCALDE, C.R.; ANDRADE, P.; MALHEIROS, E.B. Avaliação dos milhos inteiro, moído e sua mistura no desempenho de novilhos em confinamento. In: REUNIÃO ANUAL DA SOCIEDADE BRASILEIRA DE ZOOTECNIA, 37., 2000, Viçosa. Anais... Viçosa: Sociedade Brasileira de Zootecnia, 2000. (CD-ROM)

CHANEY, A.L.; MARBACH, E.P. Modified reagents for determination of urea and ammonia. Clinical Chemistry, v.8, p.130-132, 1962.

DelCURTO, T.; COCHRAN, R.C.; CORAH, L.R. et al. Supplementation of dormant Tallgrass-Prarie forage: II. Performance and forage utilization characteristics in grazing beef cattle receiving supplements of different protein concentrations. Journal of Animal Science, v.68, n.2, p.532-542, 1990.

DETMANN, E.; PAULINO, M.F.; LEÃO, M.I. et al. Níveis de proteína em suplementos múltiplos para terminação de bovinos mestiços em pastejo: ganho de peso. In: REUNIÃO ANUAL DA SOCIEDADE BRASILEIRA DE ZOOTECNIA, 38., 2001, Piracicaba. Anais... Piracicaba: Sociedade Brasileira de Zootecnia, 2001. p.1198-1199.

ESCUDER, J. Experimento com animais em pastejo. Revista da Sociedade Brasileira de Zootecnia, v.4, p.158-176, 1975.

EUCLIDES, V.P.B.; EUCLIDES FILHO, K.; ARRUDA, Z.J. et al. Desempenho de novilhos em pastagens de Bracharia decumbens submetidos a diferentes regimes alimentares. Revista Brasileira de Zootecnia, v.27, v.2, p.246-25, 1997.

HOOVER, W.H. Chemical factors involved in ruminal fiber digestion. Journal of Dairy Science, v.68, n.1, p.40-44, 1986.

KOWALCZYK, J.; ØRSKOV, E.R.; ROBINSON, J.J. et al. Effect of fat supplementation on voluntary food intake and rumen metabolism in sheep. British Journal Nutrition, v.37, n.2, p.251-257, 1977.

LENG, R.A. Factors affecting the utilization of "poor-quality" forages by ruminants particularly under tropical conditions. Nutrition Research Review, v.3, n.3, p.277-303, 1990.

McMENIMAN, N.P. Methods of estimating intake of grazing animals. In: SIMPÓSIO SOBRE TÓPICOS ESPECIAIS EM ZOOTECNIA. REUNIÃO ANUAL DA SOCIEDADE BRASILEIRA DE ZOOTECNIA, 34., 1997, Juiz de Fora. Anais... Juiz de Fora: Sociedade Brasileira de Zootecnia, 1997. p.131-168.

MINSON, D.J. Forage in ruminant nutrition. San Diego: Academic Press, 1990. 483p.

NAGARAJA, T.G.; NEWBOLD, C.J.; Van NEVEL, C.J. et al. Manipulation of ruminal fermentation. In: HOBSON, P.N.; STEWART, C.S. (Eds.) The rumen microbial ecosystem. 2.ed. London: Blackie Academic \& Professional, 1997. p.523-632.

NATIONAL RESEARCH COUNCIL - NRC. Nutrient requirements of dairy cattle. 6.ed. Washington, D.C.: Academic Press, 1988. 158p.

PAULINO, M.F. Estratégias de suplementação para bovinos em pastejo. In: SIMPÓSIO DE PRODUÇÃO DE GADO DE CORTE, 1., 1999, Viçosa, MG. Anais... Viçosa: Universidade Federal de Viçosa, 1999. p.137-156. 
PAULINO, M.F. Suplementação de bovinos em pastejo. Informe Agropecuário, v.21, n.205, p.96-106, 2000.

SANTOS, E.D.G. Terminação de bovinos em pastagem de Brachiaria decumbens Stapf, durante a estação seca, alimentados com diferentes concentrados. Viçosa, MG: Universidade Federal de Viçosa, 2001. 163p. Dissertação (Mestrado em Zootecnia) - Universidade Federal de Viçosa, 2001.

SEARLE, S.R. Linear models. New York: John Wiley \& Sons, 1971. 532p.

SILVA, D.J. Análise de alimentos (métodos químicos e biológicos). 2.ed. Viçosa: Universidade Federal de Viçosa. 1990. 256p.

SNIFFEN, C.J.; O'CONNOR, J.D.; VAN SOEST, P.J. et al. A net carbohydrate and protein system for evaluating cattle diets: II. Carbohydrate and protein availability. Journal of Animal Science, v.70, n.10, p.3562-3577, 1992.
THIAGO, L.L.S.; SILVA, J.M.; FEIJÓ, G.L.D. et al. Efeito da restrição alimentar no desempenho e características de carcaça de bovinos confinados. In: REUNIÃO ANUAL DA SOCIEDADE BRASILEIRA DE ZOOTECNIA, 35., 1998, Botucatu. Anais... Botucatu: Sociedade Brasileira de Zootecnia, 1998. (CD-ROM)

Recebido em: 14/03/01

Aceito em: 05/11/01 